\title{
Dependence of solar radiative forcing of forest fire aerosol on ageing and state of mixture
}

\author{
M. Fiebig ${ }^{1}$, A. Stohl ${ }^{2}$, M. Wendisch ${ }^{3}$, S. Eckhardt ${ }^{2}$, and A. Petzold ${ }^{1}$ \\ ${ }^{1}$ Deutsches Zentrum für Luft und Raumfahrt Oberpfaffenhofen, Institut für Physik der Atmosphäre, Wessling, Germany \\ ${ }^{2}$ Technische Universität München, Lehrstuhl für Bioklimatologie und Immissionsforschung, Freising-Weihenstephan, \\ Germany \\ ${ }^{3}$ Leibniz-Institut für Troposphärenforschung, Leipzig, Germany
}

Received: 13 November 2002 - Published in Atmos. Chem. Phys. Discuss.: 10 March 2003

Revised: 13 June 2003 - Accepted: 18 June 2003 - Published: 30 June 2003

\begin{abstract}
During airborne in situ measurements of particle size distributions in a forest fire plume originating in Northern Canada, an accumulation mode number mean diameter of $0.34 \mu \mathrm{m}$ was observed over Lindenberg, Germany on 9 August 1998. Realizing that this is possibly the largest value observed for this property in a forest fire plume, scenarios of plume ageing by coagulation are considered to explain the observed size distribution, concluding that the plume dilution was inhibited in parts of the plume. The uncertainties in coagulation rate and transition from external to internal mixture of absorbing forest fire and non-absorbing background particles cause uncertainties in the plume's solar instantaneous radiative forcing of $20-40 \%$ and of a factor of 5-6, respectively. Including information compiled from other studies on this plume, it is concluded that the plume's characteristics are qualitatively consistent with a radiative-convective mixed layer.
\end{abstract}

\section{Introduction}

Despite considerable research effort, atmospheric aerosol remains one of the important but less understood climate forcing agents (IPCC, 2001). One source of uncertainty are the amount and efficiency of light absorbing aerosol components (Andreae, 2001). One half of the yearly emitted particulate black carbon, the predominant light absorbing component in aerosol particles, is emitted by anthropogenic and natural biomass-burning. The remaining part is emitted by fossil fuel combustion. Of the different biomass-burning sources, fires in temperate and boreal forests contribute $26-41 \%$ of the emitted black carbon mass (Penner et al., 1998).

The magnitude of the solar radiative forcing of aerosol particles containing an absorbing component depends on the concentration of that component (Haywood and Shine,

Correspondence to: M. Fiebig (Markus.Fiebig@dlr.de)
1995) and on the aerosol particles' number size distribution (Chylek and Wong, 1995). Current global circulation models often use fixed microphysical properties of the absorbing aerosol, varying only its mass loading (Penner et al., 1998; Myhre et al., 1998; Schult et al., 1997). It has been pointed out that even the sign of the radiative forcing of absorbing aerosol particles can change with the state of mixture of the absorbing component (Myhre et al., 1998). The mixture can be external with the absorbing component present as particles distinct from non-absorbing particles, or internal with the absorbing component contained within the nonabsorbing material. If the absorbing material is internally mixed, its absorption efficiency is higher compared to the externally mixed case, resulting in a more positive solar radiative forcing (Wendisch et al., 2001). When emitted, absorbing particles are usually externally mixed with non-absorbing background particles. The state of mixture shifts when absorbing aerosol particles coagulate with non-absorbing background particles during ageing. It has been argued that for black carbon, the resulting radiative forcing is, on global average, comparable in magnitude and sign with the radiative forcing of methane (Jacobson, 2001). However, the range of solar radiative forcings calculated for absorbing aerosol components assuming different particle size distributions, ageing processes and thus mixture states leaves even the sign uncertain (IPCC, 2001).

In this article, the effect of the temporal evolution of particle size distribution, state of mixture and their uncertainties on the solar radiative forcing of forest fire aerosol is considered. The influence of plume dilution receives special attention. The studied case, a plume of aerosol emitted by forest fires in Northern Canada in 1998, has been the subject of several previous works (Hsu et al., 1999; Fromm et al., 2000; Forster et al., 2001; Fiebig et al., 2002; Formenti et al., 2002a) whose results are summarised. The particle size distribution in the plume as measured over Lindenberg, Germany, during the Lindenberg Aerosol Characterisation

(C) European Geosciences Union 2003 
Experiment (LACE 98) (Ansmann et al., 2002) on 9 August 1998 is classified by briefly reviewing other measurements in such plumes, emphasizing the temporal evolution of the particle size distribution. The possibilities of several scenarios of ageing by coagulation leading to the observed mixing state and size distribution of this forest fire aerosol are investigated. Based on this case study and the results of previous studies, the uncertainty of the solar radiative forcing of the forest fire aerosol during ageing due to uncertainties in size distribution and state of mixture is quantified. Finally, a possible explanation for the observed properties of the plume is given by comparison with a radiative-convective mixed layer (Lilly, 1988).

\section{Background}

\subsection{The LACE 98 forest fire aerosol case}

The aerosol plume investigated here was observed over Lindenberg, $80 \mathrm{~km}$ south-east of Berlin, Germany, during the Lindenberg Aerosol Characterisation Experiment (LACE 98) (Ansmann et al., 2002) on 9 and 10 August, 1998. Lidar backscatter profiles (Forster et al., 2001; Fiebig et al., 2002; Wandinger et al., 2002) show this aerosol layer to consist of two sub-layers from $3.8-4.3 \mathrm{~km}$ and $4.7-5.2 \mathrm{~km}$ above sea level (ASL) on 9 August, 1998. Backward trajectory calculations (Wandinger et al., 2002; Forster et al., 2001) as well as aerosol index data obtained by the Total Ozone Mapping Spectrometer (TOMS) on the Earth Probe satellite (Fiebig et al., 2002; Hsu et al., 1999) as well as model tracer studies (Forster et al., 2001) relate the aerosol layer to forest fires in northern Canada near Great Bear Lake, Northwest Territories. All sources indicate an age of the forest fire aerosol of 6-7 days at the time of arrival above Lindenberg. The same plume was also sampled on 14 August, 1998 over Greece during the Scientific Training and Access to Aircraft for Atmospheric Research Throughout Europe (STAARTE-MED) experiment (Formenti et al., 2002a).

At Lindenberg, the two sub-layers were sampled in-situ by instruments on-board two research aircraft, the Deutsches Zentrum für Luft- und Raumfahrt (DLR) Falcon, a remodeled business jet, and the Partenavia, a twin-prop engine aircraft, operated by the Leibniz-Institut für Troposphärenforschung (IfT), Leipzig, Germany (Petzold et al., 2002; Wendisch et al., 2002). On-board the Falcon, in-situ measurements of the particle number density and size distribution of both sub-layers were conducted with two Condensation Particle Counters (type TSI 3760A), which received their sample through an inlet mounted in the fuselage roof, and two wing-mounted optical particle counters (OPCs): a Passive Cavity Aerosol Spectrometer Probe (PCASP-100X) and a Forward Scattering Spectrometer Probe (FSSP-300, both manufactured by Particle Measuring Systems, Inc., Boulder, CO, USA). OPCs infer the diameter of single aerosol parti-

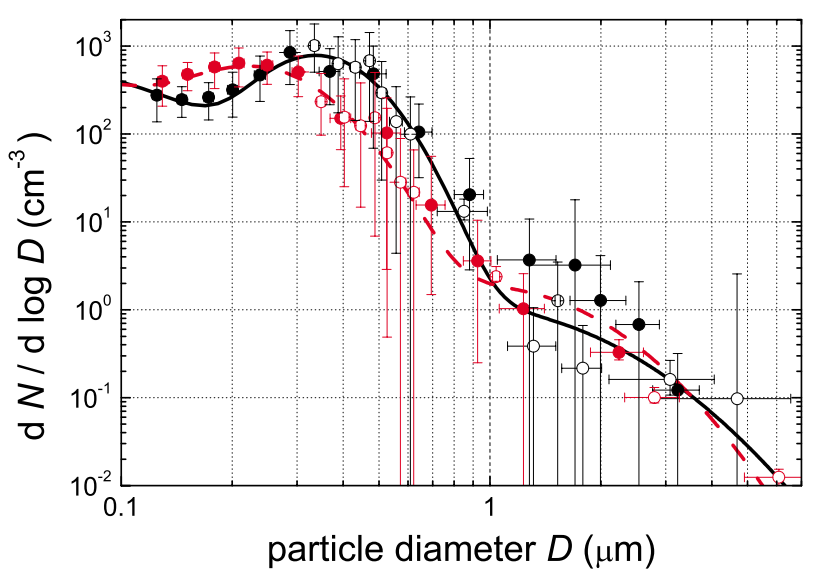

Fig. 1. Particle number size distributions within the upper sublayer (red data points) and lower sub-layer (black data points) of the aerosol from biomass-burning over Lindenberg, Germany on 9 August 1998. Closed symbols indicate PCASP, open symbols FSSP-300 data points. Both distributions contain more than $1000 \mathrm{~s}$ of data. The three modal logarithmic normal distributions fitted to the size distributions of the lower and upper sub-layers appear solid and dashed, respectively.

cles from the intensity of light scattered by the particle into a fixed solid angle while it crosses a laser beam. Besides the dependence on particle diameter $D$, the intensity of the scattered light depends also on the complex particle refractive index $m$ and, to a lower degree, on the particle shape. Both factors were taken into account in the data analysis (Fiebig et al., 2002). The PCASP-100X dries the particles to a relative humidity $(R H)$ of $\approx 20 \%$ during sampling whereas the FSSP-300 measures in-situ. The difference in sampling conditions between the two OPCs is insignificant in the present case because $R H$ values below $20 \%$ were detected in both sub-layers.

Figure 1 shows the particle number size distributions measured in the two sub-layers on 9 August 1998 including the uncertainties due to varying $m$ (horizontal bars) and counting statistics (vertical bars). For this graph, the aerosol has been assumed to consist of ammonium sulphate and soot internally mixed with a refractive index of $1.6+0.03 i$. To obtain the uncertainty in $D, m$ was varied by $0.1+0.006 i$. The particle size distributions consist of the Aitken, accumulation, and coarse modi, with the accumulation mode clearly dominating. By using Mie-calculation and integrating the particle extinction cross-section over the particle size distribution (Fiebig et al., 2002), the accumulation mode is found to contribute more than $90 \%$ to the layer's extinction coefficient at $\lambda=550 \mathrm{~nm}$. A significant difference in $D$ of the maximum particle concentration of the accumulation mode is obvious between the upper and lower sub-layer. A three-modal logarithmic normal distribution was fitted to the two particle size distributions using a procedure described in Fiebig 
Table 1. Integral number concentration $N$, number median particle diameter $\bar{D}$, and geometric standard deviation $\sigma_{g}$ of logarithmic normal distributions fitted to distributions of Fig. 1

\begin{tabular}{lccc}
\hline distribution/mode & $\mathrm{N}\left[\mathrm{cm}^{-3}\right]$ & $\bar{D}[\mu \mathrm{m}]$ & $\sigma_{g}$ \\
\hline lower sub-layer & & & \\
Aitken & $410 \pm 60$ & $0.057 \pm 0.01$ & $2.0 \pm 0.3$ \\
accumulation & $250 \pm 100$ & $0.34 \pm 0.03$ & $1.35 \pm 0.1$ \\
coarse & $0.7 \pm 1.0$ & $0.9 \pm 0.7$ & $1.9 \pm 0.5$ \\
upper sub-layer & & & \\
Aitken & $400 \pm 50$ & $0.050 \pm 0.01$ & $2.0 \pm 0.3$ \\
accumulation & $220 \pm 60$ & $0.23 \pm 0.02$ & $1.45 \pm 0.1$ \\
coarse & $1.0 \pm 1.0$ & $1.0 \pm 0.3$ & $1.7 \pm 0.3$ \\
\hline
\end{tabular}

et al. (2002). The resulting parameterised functions are characterised by the integral particle number concentration $N$, the median particle diameter $\bar{D}$, and the geometric standard deviation $\sigma_{g}$ for each mode.

These parameters are given in Table 1 for all three modi of both sub-layers as measured on 9 August 1998. The difference of the accumulation modes between the two sub-layers is visible in Fig. 1 and is reflected in a significant difference in the respective number median particle diameters $\bar{D}$.

Besides the particle size distribution, the measurements on both aircraft also included the particle absorption coefficient, measured with a particle soot absorption photometer (PSAP, Radiance Research, Seattle, USA), and the particle scattering coefficient, measured with a nephelometer (also Radiance Research) to correct the PSAP measurement for its crossdependence to particle scattering (Bond et al., 1999). As the PSAP requires an averaging time $>30 \mathrm{~s}$ and the DLR Falcon, due to its high true air speed, could not stay inside the filamentary structured layers long enough, the values measured on-board the slower flying Partenavia were used in the analysis. Also, no absorption coefficients are available for the upper sub-layer as the Partenavia has a ceiling of $\approx 4 \mathrm{~km}$. A peak value of $2.0 \pm 0.8 \mathrm{~m}^{-5}$ was measured in the lower sublayer on 9 August 1998.

In Fiebig et al. (2002), the particle size distribution measured in the lower sub-layer during the night from 9 to 10 August 1998 was used to calculate the layer's spectral lidar backscatter coefficient using Mie-theory. Based on a filter sample obtained in the layer on-board the Falcon and analyzed by the Technical University Darmstadt, Germany, ammonium sulphate and soot were assumed as components of the particles in the lower sub-layer. The spectral refractive index of ammonium sulphate (taken from Toon et al., 1976) represents well the non-absorbing components found in the sample and soot (refractive index taken from Ackerman and Toon, 1981), apart from a small fraction of iron oxides, accounted for the largest part of the absorbing component in the particles. The calculation was done assuming an inter-

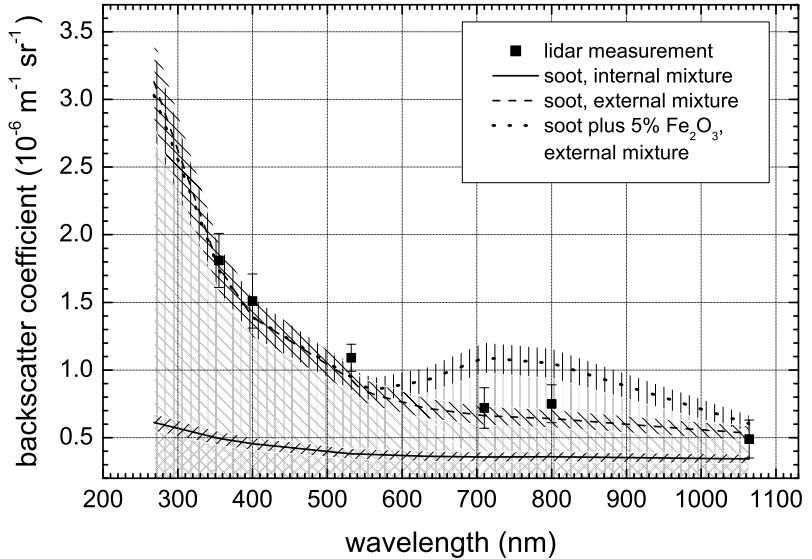

Fig. 2. Comparison of spectral lidar backscatter coefficient for lower sub-layer during the night from 9 to 10 August 1998, calculated from in-situ measurements of the particle microphysical properties and measured by the IfT multi-wavelength lidar (quoted from Fiebig et al., 2002, reproduced by permission of the American Geophysical Union).

nal mixture of the two components or assuming an external mixture. The state of mixture refers here to the optical aerosol properties and includes the possibility that the absorbing particles are internally mixed with respect to their chemical composition. Each time, the soot fraction was chosen such that the calculated absorption coefficient matched the PSAP measurement. The calculated backscatter coefficient was compared with the one measured by the groundbased multi-wavelength lidar of the IfT which was operated in Lindenberg.

The result, quoted in Fig. 2, clearly indicates that the absorbing and non-absorbing components of the lower sublayer were externally mixed. This fact was taken into account throughout the reported analysis. The size distribution (Fig. 1) was validated by calculating the instrument responses of the OPCs on the externally mixed aerosol and comparison with the measured instrument responses (Fiebig et al., 2002). A similar analysis for the upper sub-layer was not possible as there was no measurement for the absorption coefficient available. This result can also be applied to the aerosols measured during the day of 9 August 1998, which are described in Table 1 and Fig. 1, because the morphology of the forest fire aerosol layer as a whole varied little between the two measurements.

2.2 Other in-situ measurements of particle size distributions within forest fire plumes

In order to classify the results obtained for the LACE 98 forest fire aerosol, a look at the extensive set of measurements of particle microphysical properties in forest fire plumes is useful. The focus will be put on the particle size distribution as a function of aerosol age. 
Table 2. Compilation of Parameters of Log-Normal Distributions Fitted to Accumulation Mode Particle Size Distributions Measured in Aerosols Originating from Forest or Vegetation Fires.

\begin{tabular}{|c|c|c|c|c|c|c|c|c|}
\hline experiment & location & fuel-type & reference & plume age & $\bar{D}_{a c c}[\mu \mathrm{m}]$ & $N_{\text {acc, ave }}\left[\mathrm{cm}^{-3}\right]$ & $N_{a c c, \max }\left[\mathrm{cm}^{-3}\right]$ & $\sigma_{g, a c c}$ \\
\hline TRACE-A & Brazil & grass/shrub & Anderson et al. (1996) & "source region" & $0.20-0.26$ & 2220 & 18000 & 1.53 \\
\hline TRACE-A & Southern Africa & grass/shrub & Anderson et al. (1996) & "source region" & $0.19-0.28$ & 2140 & 19500 & 1.64 \\
\hline TRACE-A & Brazil & grass/shrub & Anderson et al. (1996) & $\begin{array}{l}\text { "continental } \\
\text { outflow" }\end{array}$ & 0.23 & 1000 & 2000 & 1.45 \\
\hline TRACE-A & Southern Africa & grass/shrub & Anderson et al. (1996) & $\begin{array}{l}\text { "continental } \\
\text { outflow" }\end{array}$ & 0.24 & 1000 & 2000 & 1.5 \\
\hline TRACE-A & Mid-South Atlantic & grass/shrub & Anderson et al. (1996) & $\geq 5 \mathrm{~d}$ & $0.17,0.23$ & 200 & 1000 & 1.3 \\
\hline SAFARI-92 & Southern Africa & $\begin{array}{l}\text { grass/shrub, mid- } \\
\text { burning season }\end{array}$ & Le Canut et al. (1996) & $\begin{array}{l}\text { "source region", } \\
\text { "younger" }\end{array}$ & 0.18 & 2000 & 2500 & ? \\
\hline SAFARI-92 & Southern Africa & $\begin{array}{l}\text { grass/shrub, mid- } \\
\text { burning season }\end{array}$ & Le Canut et al. (1996) & $\begin{array}{l}\text { "source region", } \\
\text { "older" }\end{array}$ & 0.21 & 2000 & 2500 & ? \\
\hline SAFARI-92 & Southern Africa & $\begin{array}{l}\text { grass/shrub, late- } \\
\text { burning season }\end{array}$ & Le Canut et al. (1996) & $\begin{array}{l}\text { "source region", } \\
\text { "younger" }\end{array}$ & 0.15 & 1000 & 2000 & ? \\
\hline SAFARI-92 & Southern Africa & $\begin{array}{l}\text { grass/shrub, late- } \\
\text { burning season }\end{array}$ & Le Canut et al. (1996) & $\begin{array}{l}\text { "source region", } \\
\text { "older" }\end{array}$ & 0.17 & 1000 & 2000 & ? \\
\hline SCAR-C & North America ${ }^{1}$ & logging leftovers & Gassó and Hegg (1999) & $\approx 5 \min$ & 0.12 & 400000 & $?$ & 1.7 \\
\hline SCAR-C & North America ${ }^{1}$ & logging leftovers & Gassó and Hegg (1999) & $1.8 \mathrm{~h}$ & 0.24 & 25600 & $?$ & 1.4 \\
\hline SCAR-B & Brazil & cerrado & Reid and Hobbs (1998) & "few minutes" & 0.10 & $<150000$ & $?$ & 1.91 \\
\hline SCAR-B & Brazil & grass & Reid and Hobbs (1998) & "few minutes" & 0.10 & $<150000$ & $?$ & 1.79 \\
\hline SCAR-B & Brazil & smoldering forest & Reid and Hobbs (1998) & "few minutes" & 0.10 & $<150000$ & $?$ & 1.77 \\
\hline SCAR-B & Brazil & flaming forest & Reid and Hobbs (1998) & "few minutes" & 0.13 & $<150000$ & $?$ & 1.68 \\
\hline SCAR-B & Brazil & forest, slash ${ }^{2}$ & Reid et al. (1998) & $<1 \mathrm{~d}$ & $0.12(\max .: 0.17)^{4}$ & 100000 & 600000 & $1.74-1.85$ \\
\hline SCAR-B & Brazil & rain forest ${ }^{3}$ & Reid et al. (1998) & $2-3 \mathrm{~d}$ & $0.19(\max .: 0.25)^{4}$ & 5000 & 10000 & $1.63-1.68$ \\
\hline STAAARTE & Greece $^{5}$ & boreal forest & Formenti et al. (2002a) & $>6 \mathrm{~d}$ & 0.20 & 1800 & 2200 & 1.43 \\
\hline LACE 98 & Central Germany & boreal forest & this article & $6-7 d$ & $0.23,0.34$ & 220,250 & 280,350 & $1.45,1.35$ \\
\hline
\end{tabular}

1 The prescribed fire referred to here is termed Quinault fire in the SCAR-C literature.

2 The values are composed of data measured at Marabá and Cuiabá (plume of local origin).

3 The values are composed of data measured at Cuiabá (transported plume) and Porto Velho.

4 Average and encountered maximum values are stated separately.

5 Location of measurement, origin of plume in Northern Canada, but possible influence by local biomass-burning or continental anthropogenic sources (Formenti et al., 2002b).

The Biomass Burning Airborne and Spaceborne Experiment in the Amazonas (BASE-A, Kaufman et al., 1992) reported particle effective radii and optical depth measured by ground-based and airborne sun photometers in Brazilian grassland and deforestation fires, while the follow-up experiment BASE-B (Ward et al., 1992) one year later only stated the particulate mass of particles with $D<2.5 \mu \mathrm{m}$ (PM2.5) at the ground. The Southern Tropical Atlantic Region Experiment (STARE, Andreae et al., 1996), encompassing the Transport and Atmospheric Chemistry near the Equator - Atlantic (TRACE A, Fishman et al., 1996) experiment which conducted measurements in plumes from biomass-burning over Brazil, the Southern Atlantic, and Southern Africa, and the Southern African Fire - Atmosphere Research Initiative (SAFARI-92, Lindesay et al., 1996), focussing on the Southern African source regions, reported detailed size distributions of the particles in plumes measured using airborne insitu instruments while the project was focused on ozone producing gas phase chemistry. The Smoke, Clouds, and Radi- ation - California (SCAR-C, Kaufman et al., 1996) project and the Boreal Ecosystem-Atmosphere Study (BOREAS, Sellers etal., 1997) are of the few experiments to provide information on aerosol produced by forest fires in temperate regions of the globe. SCAR-C yielded microphysical particle properties from airborne measurements in plumes of prescribed fires on areas which had previously been cleared by logging while BOREAS reported particle size distributions in plumes of natural forest fires inverted from sun photometry. The probably most detailed study focussing specifically on microphysical particle properties, precursor gases, and their variation during plume ageing in tropical forest and biomass fires, including airborne in-situ measurements, was the Smoke, Clouds and Radiation-Brazil (SCAR-B, Kaufman et al., 1998) experiment which was conducted in 1995 in four main locations in Brazil.

In reviewing the results of the mentioned projects, those which conducted airborne in situ measurements using OPCs or a differential mobility particle sizer (DMPS) are of special 
interest. Sun photometry yields size distributions which represent the vertical column and thus air masses with quite different compositions and histories. Also, particle size distributions inverted from sun photometer data are normally limited to $D>0.2 \mu \mathrm{m}$ which is not sufficient to fully resolve the accumulation mode size range. All mentioned experiments found this size range to dominate both the number size distribution and the optical properties of forest fire aerosols. Table 2 summarizes the parameters of log-normal distributions fitted to the measured accumulation mode number size distributions as reported by the SAFARI, TRACE-A, SCAR-C, SCAR-B, and STAAARTE-MED experiments as a function of fuel type and age of the aerosol plume as far as stated in the references.

The SAFARI campaign found the accumulation mode particle number mean diameter $\bar{D}_{a c c}$ to increase with increasing plume age and to decrease towards the end of the burning season where the particle concentrations decreased. While this correlation could not be reproduced during the TRACEA project due to a large variability of the size distribution properties close to the source, the variability as well as the accumulation mode geometric standard deviation $\sigma_{g}$, acc decreased with plume age. As described in Anderson et al. (1996), two air-masses were layered on top of each other in the tropospheric column sampled over the Mid-South Atlantic during TRACE-A, the lower one $(\approx 2-6 \mathrm{~km})$ being connected with Southern African sources and the upper one $(>6 \mathrm{~km}$ ) with South American sources. Although two sets of particle size distributions with different values for $\bar{D}_{a c c}$ can be distinct in the corresponding data, it is not stated in the reference if these can be connected with the different air masses.

The correlation of increasing $\bar{D}_{a c c}$, decreasing $\sigma_{g}$, acc and decreasing variability in these parameters with increasing plume age could be confirmed during the SCAR-C and SCAR-B experiments. Different from the previous studies, a detailed determination of the plume age was included in the data analysis during these projects. During SCAR-B, little variation of $\bar{D}_{a c c}$ was found close to the forest or biomass fire source, but considerable variation in $N_{a c c}$, the accumulation mode integral particle number concentration, and $\sigma_{g, a c c}$. Particle samples on filters analyzed by transmission (TEM) and scanning electron microscopy (SEM) (Reid and Hobbs, 1998) showed that most particles were chemically internal mixtures of black carbon with a shell of organic compounds. A scale analysis of gas-to-particle conversion and coagulation during plume ageing yielded that condensational growth is the dominating ageing process up to 1-2 days after emission. After the concentration of condensable gases has decreased enough and the aerosol has transformed into a so called regional haze, coagulation dominates the ageing process in the forest fire plumes measured during SCAR-B (Reid et al., 1998). Mean values for $\bar{D}_{a c c}$ and $\sigma_{g, a c c}$ showed little variation at this point with respect to plume origin with values centered around $0.19 \mu \mathrm{m}$ and 1.65 , respectively.
The measurements of Formenti etal. (2002a) during STAAARTE-MED over Greece yielded values of $0.20 \mu \mathrm{m}$ for $\bar{D}_{a c c}$ and 1.43 for $\sigma_{g}$, acc in the same plume that was observed during LACE 98 five days before. However, the plume parts sampled during STAAARTE-MED and LACE 98 are likely to have seen different transport paths and resulting rates of turbulent dilution. Formenti et al. (2002b) point out that the plume part over Greece could have been influenced by local biomass-burning or continental anthropogenic sources.

When comparing the properties of the LACE 98 plume with those summarized in Table 2, it is obvious that the LACE 98 forest fire aerosol is among those with the longest atmospheric residence times encountered. Also, as far as reported in the literature quoted in Table 2, the forest fire aerosol encountered in the lower sub-layer on 9 August 1998 during LACE 98 is likely to exhibit the largest accumulation mode number median diameter ever measured.

\section{Ageing processes of forest fire aerosol}

The LACE 98 forest fire aerosol layer had rather special microphysical properties - long atmospheric residence time of approximately 7 days, large number mean diameter of the accumulation mode $\bar{D}_{a c c}$, external mixture of particles with respect to optical properties. In the following, it is discussed how such an aerosol can be produced, especially concerning the value of $\bar{D}_{a c c}$ in the lower sub-layer.

The observed properties could be the result of processes at the source of the forest fire plume. However, seeing the extensive set of measurements underlying the values in Table 2 and given the fact that such an aerosol has not been observed so far in any source region of forest fire aerosol, this option is unlikely.

In order to reproduce the measurements of $\bar{D}_{a c c}$, the theory on the particle ageing processes in Reid et al. (1998) is applied. There, it is shown that condensational growth of particles dominates aerosol ageing up to 1-2 days after plume emission, whereas coagulation is the dominating ageing process thereafter. This behaviour is comprehensible as the supply of condensable species and precursor gases emitted into the plume is limited once the plume has left the vicinity of the source. The rate of particle coagulation is described by the equation (Seinfeld and Pandis, 1998)

$$
\begin{aligned}
& \frac{\partial n(D, t)}{\partial t}=\frac{1}{2} \int_{0}^{D} K\left(D-D^{\prime}, D^{\prime}\right) n\left(D^{\prime}\right) n\left(D-D^{\prime}\right) d D^{\prime} \\
& -n(D, t) \int_{0}^{\infty} K\left(D, D^{\prime}\right) n\left(D^{\prime}, t\right) d D^{\prime}
\end{aligned}
$$

where $n(D, t)$ denotes the particle number concentration (in units of $\mathrm{cm}^{-3} \mu \mathrm{m}^{-1}$ ) as function of $D$ and time $t$ and $K\left(D, D^{\prime}\right)$ the coagulation coefficient which quantifies the efficiency of Brownian particle motion to bring two particles of 
diameters $D$ and $D^{\prime}$ to collision. $K$ is a function of temperature $T$ and pressure $p$ (Seinfeld and Pandis, 1998). In Eq. (1), the first integral describes the coagulation of particles smaller than $D$ to those of diameter $D$, the second term the coagulation of particles of diameter $D$ with other particles to form ones larger than $D$. Equation (1) is integrated numerically for a known initial $n(D, t)$ and given $T$ and $p$.

The measurements collected in Table 2 are used to initialize such an integration and to test which circumstances are necessary to produce an aerosol as observed during LACE 98. The data provided by the SCAR-C and SCAR-B projects are suitable for this purpose because they provide detailed information on the age of the sampled forest fire aerosols as compared with the other data in Table 2. Considering the source properties of the aerosols sampled during these campaigns, the SCAR-B source of the sampled regional hazes should be more comparable to the fires that caused the LACE 98 aerosol layer. The LACE 98 source fires burned more than $10^{6}$,ha of boreal forest over a period of 6 days (Forster et al., 2001) while the SCAR-C Quinault fire had a total size of 19.4 ha which burned within $\approx 9 \mathrm{~h}$ (Hobbs et al., 1996). Also, the fuel for the SCAR-C Quinault fire consisted of logging debris while the fuel of the SCAR-B regional hazes as well as the LACE 98 forest fire aerosol consisted of live trees, although the tree species were certainly different.

Since the coagulation rate is roughly proportional to the square of the particle concentration, knowledge about other processes influencing the particle concentration, especially the plume dilution, is necessary. In the far field around a point source, a plume dilution proportional to $t^{-1}$ is commonly used where $t$ is the time after emission (Arya, 1999).

To study different scenarios of the microphysical development of the LACE 98 forest fire aerosol, Table 3 summarizes the results of coagulation calculations for a single lognormally distributed accumulation mode with various initial values of the modal particle concentration $N_{\text {acc }}\left(t_{\text {start }}\right)$, the modal number mean diameter $\bar{D}_{a c c}\left(t_{\text {start }}\right)$, and the modal geometric standard deviation $\sigma_{g}$, acc $\left(t_{\text {start }}\right)$ as well as different starting times of the calculations $t_{\text {start }}$ (time of reaching the regional haze state) and assumptions on plume dilution. All calculations end 6 days after emission $\left(t_{\text {end }}=6\right.$ days), representing the forest fire aerosol sampled during LACE 98. The corresponding accumulation mode parameters are given as $N_{a c c}\left(t_{\text {end }}\right), \bar{D}_{a c c}\left(t_{\text {end }}\right)$, and $\sigma_{g, a c c}\left(t_{\text {end }}\right)$. The plume dispersion is varied between a dilution proportional to $t^{-1}$ and no dilution.

The scenarios 1-8 represent the regional haze aerosols measured during SCAR-B and utilize the fact that $\bar{D}_{a c c}$ and $\sigma_{g, a c c}$ were rather constant for different locations. $N_{\text {acc }}\left(t_{\text {start }}\right)$ is varied between the measured average value of $5000 \mathrm{~cm}^{-3}$ and the maximum value of $10000 \mathrm{~cm}^{-3}$. The starting time of the calculation $t_{\text {start }}$ is varied within the range of ages given for regional hazes for SCAR-B. As a result, only the scenarios that assume the high initial particle

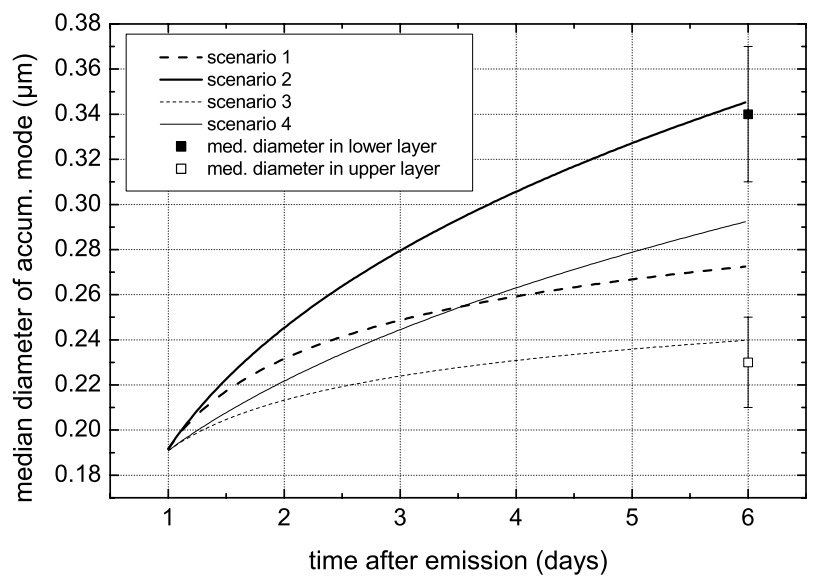

Fig. 3. Temporal development of accumulation mode median diameter for an aerosol from biomass-burning due to coagulation for different assumptions on initial concentration and dispersion during ageing.

concentration and no plume dilution are able to reproduce the value of $\bar{D}_{a c c}$ which was observed in the lower sub-layer of the LACE 98 forest fire aerosol. The values of $N_{a c c}\left(t_{\text {end }}\right)$ cannot be compared with the values of $N_{a c c}$ measured during LACE 98 as the plume over Lindenberg was in the stage of final dissolving and $N_{a c c}$ therefore highly variable in space and time. $\bar{D}_{a c c}$ instead is less sensitive to recent dilution and reflects the microphysical history of the aerosol on the order of days.

To clarify the differences between the scenarios, Fig. 3 shows a time series of $\bar{D}_{a c c}$ according to scenarios $1-4$, representing different initial concentrations and dilutions. The values of $\bar{D}_{a c c}$ at the end of the calculation are compared with those measured in the lower and upper sub-layer over Lindenberg. Scenarios 5-8 are omitted for clarity as the variation of $t_{\text {start }}$ does not cause significant changes in $\bar{D}_{a c c}\left(t_{\text {end }}\right)$.

The result of little or almost no dilution in parts of the plume of the LACE 98 forest fire aerosol layer while being transported from its source to Lindenberg is tested further. Scenarios 9 and 10 in Table 3 consider the effect of a simultaneous presence of particles in the coarse mode size range. The parameters of the log-normal mode assumed for the coarse mode aerosol are taken from Reid and Hobbs (1998) and were measured in young forest and biomass fires of a few minutes age. From the modal parameters at the end of the calculation, compared with scenarios 1 and 2, it is obvious that the presence of a coarse mode has virtually no effect on the coagulation rate within the accumulation mode particles. This result is in agreement with the findings of Reid et al. (1998) who investigated filters sampled in the SCAR-B plumes with a scanning electron microscope and found at most 50 accumulation mode or smaller particles on the surface of the coarse mode particles. Scenarios 
Table 3. Change of accumulation mode parameters of forest fire aerosol due to ageing by coagulation for various assumptions on initial conditions and dilution during transport

\begin{tabular}{ccccccc|cc}
\hline Scenario & $\begin{array}{c}t_{\text {start }} \\
{[\text { days }]}\end{array}$ & $\begin{array}{c}N_{a c c}\left(t_{\text {start }}\right) \\
{\left[\mathrm{cm}^{-3}\right]}\end{array}$ & $\begin{array}{c}\bar{D}_{a c c}\left(t_{\text {start }}\right) \\
{[\mu \mathrm{m}]}\end{array}$ & $\sigma_{g, a c c}\left(t_{\text {start }}\right)$ & dilution & $\begin{array}{c}N_{\text {acc }}\left(t_{\text {end }}\right) \\
{\left[\mathrm{cm}^{-3}\right]}\end{array}$ & $\begin{array}{l}\bar{D}_{a c c}\left(t_{\text {end }}\right) \\
{[\mu \mathrm{m}]}\end{array}$ & $\sigma_{g, \text { acc }}\left(t_{\text {end }}\right)$ \\
\hline 1 & 1 & 10000 & 0.19 & 1.6 & yes & 751 & 0.27 & 1.51 \\
2 & 1 & 10000 & 0.19 & 1.6 & no & 2510 & 0.34 & 1.47 \\
3 & 1 & 5000 & 0.19 & 1.6 & yes & 504 & 0.24 & 1.54 \\
4 & 1 & 5000 & 0.19 & 1.6 & no & 1900 & 0.29 & 1.49 \\
5 & 2 & 10000 & 0.19 & 1.6 & yes & 1349 & 0.28 & 1.50 \\
6 & 2 & 10000 & 0.19 & 1.6 & no & 2878 & 0.33 & 1.47 \\
7 & 2 & 5000 & 0.19 & 1.6 & yes & 931 & 0.25 & 1.53 \\
8 & 2 & 5000 & 0.19 & 1.6 & no & 2128 & 0.28 & 1.50 \\
91 & 1 & 10000 & 0.19 & 1.6 & yes & 751 & 0.27 & 1.51 \\
$10^{1}$ & 1 & 10000 & 0.19 & 1.6 & no & 2510 & 0.34 & 1.47 \\
$11^{2}$ & 1 & 10000 & 0.19 & 1.6 & yes & 1240 & 0.27 & 1.48 \\
$12^{2}$ & 1 & 10000 & 0.19 & 1.6 & no & 3310 & 0.38 & 1.44 \\
\hline
\end{tabular}

${ }^{1}$ The additional coarse mode assumed for these calculations has the log-normal parameters $N_{\text {acc }}\left(t_{\text {start }}\right)=0.4 \mathrm{~cm}^{-3}, \bar{D}_{\text {acc }}\left(t_{\text {start }}\right)=1.4 \mu \mathrm{m}$, and $\sigma_{g, a c c}\left(t_{\text {start }}\right)=1.6$. Except for dilution in scenario 9, the coarse mode parameters do not change significantly throughout the calculation.

${ }^{2}$ The additional Aitken-mode assumed for these calculations has the log-normal parameters $N_{a c c}\left(t_{s t a r t}\right)=9 \cdot 10^{6} \mathrm{~cm}^{-3}$, $\bar{D}_{a c c}\left(t_{\text {start }}\right)=0.018 \mu \mathrm{m}$, and $\sigma_{g}$,acc $\left(t_{\text {start }}\right)=1.5$. At $t_{\text {end }}$, the Aitken-mode particles essentially vanished, leaving the accumulation mode slightly more asymmetric as compared with the scenarios 1 and 2 .

11 and 12 investigate the effect of a significant particle mode in the Aitken size range which is still present in the regional haze although gas-to-particle conversion should have ceased by that time. The modal parameters of the Aitken-mode were measured directly over the SCAR-C Quinault fire (Gassó and Hegg, 1999), resulting in an upper limit of the effect of the Aitken-mode. This size distribution is chosen as it is the only one measured close to a fire source which shows an Aitkenmode distinct from the accumulation mode. Although the presence of the Aitken-mode causes a significant shift of $\bar{D}_{a c c}$ to larger values compared to scenarios 1 and 2 at the end of the transport period, the value of $\bar{D}_{a c c}$ observed in the lower sub-layer of the LACE 98 forest fire aerosol can still be reproduced only assuming a dilution less then proportional to $t^{-1}$.

To investigate the influence of particles contained in the dilution air on the evolution of the forest fire aerosol, all cases that include dilution were calculated once assuming particle free dilution air and once assuming a free tropospheric aerosol as dilution air. The modal parameters for the free tropospheric particle size distribution, $N_{A i t}=500 \mathrm{~cm}^{-3}, \bar{D}_{A i t}=0.047 \mu \mathrm{m}, \sigma_{g, A i t}=2.0$ for the Aitken mode, $N_{a c c}=20 \mathrm{~cm}^{-3}, \bar{D}_{a c c}=0.23 \mu \mathrm{m}, \sigma_{g, a c c}=1.4$ for the accumulation mode, were taken from the LACE 98 measurements (Petzold et al., 2002, upper tropospheric aerosol, flight M1, polar air masses approaching Lindenberg, Germany, from north-west). As a result, it is found that the assumptions on the particle size distribution in the dilution air have no significant effect on the accumulation mode parameters after 6 days of coagulation. The particles in the
Aitken mode present in addition to the accumulation mode particles in the cases with particle laden dilution air are too small to be significant with respect to aerosol optical properties.

Changes of the ambient particle concentration due to upor downlifting of the plume are not included in the coagulation calculations. The maximum uplifting obtained by trajectory calculations for the plume ranges from $2 \mathrm{~km}$ to $7 \mathrm{~km}$ altitude, which corresponds to a decrease of the particle concentration by a factor of $\approx 0.6$. However, if the particle concentration in the plume decreased due to uplifting, but a high concentration had to be maintained to produce high coagulation rates and the observed $\bar{D}_{a c c}$ value, the possible range of values of the turbulent dilution is further narrowed to smaller dilutions.

This finding of inhibited dilution in the plume corresponds with the result that absorbing and purely scattering particles were externally mixed in the lower LACE 98 sub-layer with respect to their optical properties. If this layer had experienced an early dilution and mixing with free tropospheric background aerosol, absorbing forest fire particles would have coagulated with purely scattering background particles, resulting in an optically internally mixed aerosol.

It can be concluded that the dilution of this aerosol during transport was inhibited as compared to a dilution proportional to $t^{-1}$. Apart from this result, a considerable uncertainty remains concerning the exact temporal evolution of the aerosols microphysical properties. These are caused to a large degree by not knowing the exact dilution of the layer as a function of time. The dilution in turn influences 
the coagulation rate and the efficiency by which the absorbing forest fire aerosol becomes internally mixed with purely scattering particles.

\section{Effect of ageing of forest fire aerosol on its solar ra- diative forcing}

To consider the consequences of uncertainties in the microphysical properties of forest fire plumes during ageing, the solar radiative forcing of such plumes and thus their influence on climate are investigated by calculating the solar aerosol radiative forcing at the tropopause as a function of plume age.

The model used for this purpose is a spectral, onedimensional radiative transfer model based on the matrixoperator method. For solving the radiative transfer equation for a vertically inhomogeneous atmosphere, the "Discrete Ordinate Method" for each homogeneous sub-layer is combined with the "Adding Method" for linking the sublayers. The vertical column is resolved by 250 layers below $5 \mathrm{~km}$ altitude, 7 layers between $5-12 \mathrm{~km}$ altitude, and three layers in the stratosphere. The model takes into account multiple scattering, also absorption by 7 major $\left(\mathrm{H}_{2} \mathrm{O}\right.$, $\mathrm{CO}_{2}, \mathrm{O}_{3}, \mathrm{~N}_{2} \mathrm{O}, \mathrm{CO}, \mathrm{CH}_{4}, \mathrm{O}_{2}$ ) and 21 further minor trace gas species (Wendisch et al., 2002). Temperature $T$-, pressure $p$-, and trace gas vertical profiles are taken from radio sonde observations over Lindenberg. Employing this approach to the Lindenberg conditions gives a close agreement between directly measured and calculated upwelling solar flux densities at the tropopause with a deviation of only about $1 \mathrm{Wm}^{-2}$ (Wendling et al., 2002). Also, measured columnar aerosol properties like aerosol optical depth and respective values calculated from aerosol properties measured in-situ agreed to within $\leq 16 \%$ (Petzold et al., 2002).

Scenarios 2 and 3 of Table 3 are assumed as microphysical input parameters of the forest fire aerosol as a function of time for the radiative transfer model. The forest fire aerosol layer is located between 3.8 and $4.3 \mathrm{~km}$ altitude. By this choice, different parts of the LACE 98 forest fire plume are considered as scenario 2 reproduces the value of $\bar{D}$ measured in the lower sub-layer while scenario 3 reproduces $\bar{D}$ as measured in the upper sub-layer. Since the absorbing forest fire particles are emitted externally mixed with purely scattering background particles, but become internally mixed when the respective part of the plume dissolves, scenarios 2 and 3 are both treated as ideal internal as well as external mixtures to obtain bounding values for the corresponding solar radiative forcing. Similar to the approach in Fiebig et al. (2002), the spectral refractive index of the absorbing component is represented by soot while the purely scattering component is represented by ammonium sulfate. Due to the dry state of the plume, it is not necessary to consider water as component. The soot volume fraction is taken to be $40 \%$ as observed over Lindenberg (Fiebig et al., 2002) throughout the calculations.

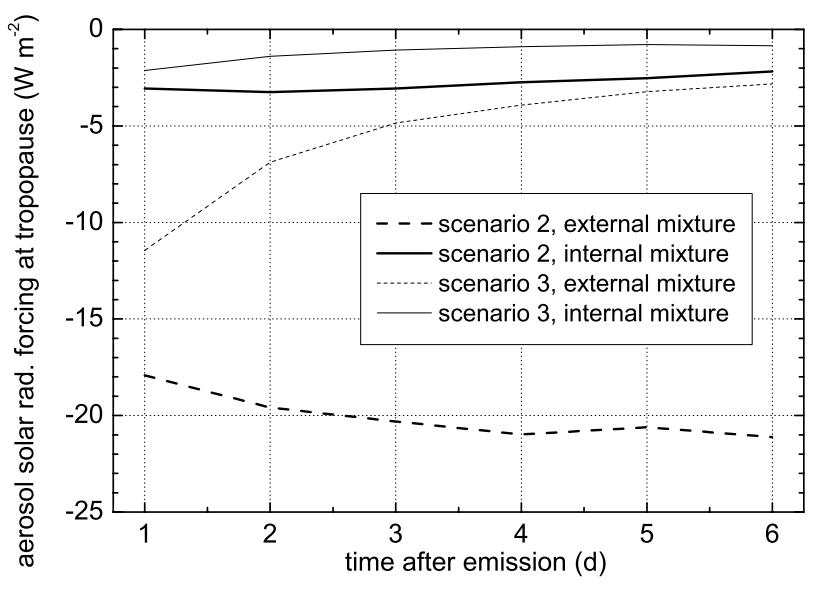

Fig. 4. Time series of the local instantaneous solar aerosol radiative forcing at the tropopause of an aerosol from biomass-burning at a constant altitude of $3.8-4.3 \mathrm{~km}$. $N, D_{m e d}$, and $\sigma_{g}$ of the aerosol's accumulation mode evolve temporally due to coagulation of the particles according to scenarios 2 (bold lines) and 3 (thin lines). The calculations for external and internal mixtures of the absorbing and purely scattering aerosol components are indicated by dashed and solid lines, respectively. All calculations have the same constant soot content found for the lower sub-layer over Lindenberg.

Apart from the forest fire plume, the aerosol properties in the remaining atmospheric column have been assumed to be the same as measured during LACE 98 on 10 August, 1998 (Petzold et al., 2002) with the boundary layer aerosol replaced by the one found in the lower free troposphere. The surface is assumed to have the spectral albedo of ocean, the solar zenith angle is fixed at $62.8^{\circ}$ representing an average daytime value for this latitude and time of year.

Figure 4 shows the calculated local, instantaneous, solar aerosol radiative forcing at the tropopause as a function of plume age. Looking at the result for scenario 2 which excludes dilution, the solar radiative forcing of the forest fire layer changes by $20-40 \%$ during transport due to coagulation. The shift from external to internal mixture causes a change of the solar radiative forcing of a factor 6.6-9.7 for scenario 2 and a factor of 3.3-5.4 for scenario 3. Both processes are essentially influenced by the dilution rate of the plume. Consequently, if the dilution properties of a given forest fire plume are not properly calculated, the resulting radiative forcing will be seriously in error.

\section{Discussion}

In finding a qualitative explanation for the properties observed in the LACE 98 forest fire plume, especially with respect to the inhibited dilution in the lower sub-layer, several processes can be suggested.

Forster et al. (2001) used the Lagrangian particle dispersion model FLEXPART to calculate the spread of an aerosol 
tracer in this plume. These authors were able to reproduce its structure as observed by lidar over Lindenberg, while the plume trajectories indicated a strong ascent in parts of the plume. This would indicate simply favourable meteorological conditions that inhibited dilution in parts of the plume. On the other hand, it is possible that dilution was inhibited by a stabilized lapse rate caused by solar absorption within the plume. This effect would already be included in the calculation by Forster et al. (2001) as it was driven by model level data of the European Center for Medium-Range Weather Forecast (ECMWF) which contain observations and thus a possible effect of the forest fire plume.

By analyzing data of the Polar Ozone and Aerosol Measurement III (POAM III) and Stratospheric Aerosol and Gas Experiment II (SAGE II) satellite instruments, Fromm et al. (2000) show that parts of the plumes of forest fires in Canada penetrated the tropopause and ascended within the stratosphere to altitudes $>15 \mathrm{~km}$ during two incidents in July and August 1998. While the July incident could partly be explained by intense deep convection in the vicinity of the fire, no such explanation is given for the August incident which corresponds to the plume observed during LACE 98. The fact that parts of the plume ascended to altitudes $>15 \mathrm{~km}$ despite the surrounding stable stratospheric lapse rate again suggests a heating of the plume by absorption of solar radiation.

To find this potential effect, the difference of the measured temperature distribution, given by the European Centre of Medium Range Weather Forecast (ECMWF) analysis of observations, and the forecast for the same point in time of initialised 24 hours before, also by the ECMWF, was investigated. The temperature difference between the analysis, including observations and thus indirectly the aerosol layer's effect, and the forecast, not including the layer's effect, should reveal a signature of the disturbance in the radiation field due to the forest fire aerosol. At 250 and $400 \mathrm{hPa}$, where the forest fire aerosol should heat the atmosphere by absorption of solar radiation, a heating of up to $6 \mathrm{~K}$ is found in the analysis as compared to the forecast for different parts of the plume. At $850 \mathrm{hPa}$, where the atmosphere should be cooled by absorption and scattering of solar radiation by the plume's aerosol aloft, a cooling of up to $-3 \mathrm{~K}$ is found at the location of the plume. However, due to a weak correlation between the plume's location and the heating and cooling patterns, a firm connection could not be established.

A possible explanation for the observed behaviour of this plume is found by comparison with the plume of the Kuwait oil fires of 1991. Herring and Hobbs (1994) use airborne measurements of the microphysical and optical particle properties inside the plume to calculate an instantaneous net heating rate of up to $3.9 \mathrm{~K} / \mathrm{h}$ at $1 \mathrm{~h}$ and $2.3 \mathrm{~K} / \mathrm{h}$ at $3 \mathrm{~h}$ plume age for a solar zenith angle of $6^{\circ}$. The observed lapse rate was stable at the bottom of the plume and almost neutral at the top while the whole plume ascended with a rate of $\approx 0.1 \mathrm{~m} / \mathrm{s}$. Both features could be explained employing a theory on radiative-convective mixed layers by Lilly (1988). According to this theory, the absorbing layer first becomes internally mixed while being heated, resulting in temperature inversions at bottom and top of the layer. With further heating, the inversion at the bottom becomes stronger and the inversion at the top decreases in strength while the magnitude of the layer increases. When the upper inversion has vanished, surrounding air entrains from above, leaving the lower part of the plume largely undiluted while the upper part is diluted. Also, the plume ascends as a whole with a rate proportional to its magnitude and inversely proportional to its horizontal width.

This theory, applied to the LACE 98 forest fire plume, would explain certain observed features. The strong temperature inversion at the plume bottom would cause the inhibited dilution and the external mixture of absorbing and purely scattering particles observed in the plume. Also, with strong dilution at the plume top and little to no dilution at the bottom of the layer, the coagulation rate would be higher at the bottom of the plume than at the top, resulting in higher values of $\bar{D}_{a c c}$ at the plume bottom than at the top, just as observed in the plume over Lindenberg (see Table 1). Finally, the plume lofting predicted by the theory could explain why parts of the plume crossed the tropopause and ascended into the stratosphere.

To obtain an estimate of the applicability of the theory used by Herring and Hobbs (1994), the radiative transfer model of Wendisch et al. (2002) was employed to calculate the net instantaneous heating rate within the LACE 98 plume assuming scenario 2, a plume age of 3 days, an external mixture of absorbing and non-absorbing components and the same soot volume fraction as inferred over Lindenberg. This choice of parameters results in a maximum likelihood estimate for the heating rate at this plume age since this scenario reproduces the aerosol observed in the lower sub-layer. The obtained value of $0.95 \mathrm{~K} / \mathrm{h}$ at $62.8^{\circ}$ solar zenith angle transfers to $2.1 \mathrm{~K} / \mathrm{h}$ at $6^{\circ}$ solar zenith angle and is therefore comparable to the heating rates obtained in the Kuwait oil fire plume. Considering all information available on this plume, it appears possible that the plume developed into a radiativeconvective mixed layer, feeding back onto its dilution, its microphysical properties and its radiative forcing.

\section{Conclusions}

The presented case study investigates a layer of absorbing aerosol observed over Lindenberg during the LACE 98 experiment. Previous studies revealed that forest fires in Northern Canada burning six days before the observation were the source of this layer. Furthermore, absorbing and nonabsorbing components were externally mixed with respect to optical properties in the lower part of the plume over Lindenberg while other parts of the plume ascended into the stratosphere. 
By using microphysical properties of forest fire aerosol close to the source from literature and considering the aerosol's ageing process by coagulation, the present study shows that dilution in the lower part of the plume over Lindenberg was inhibited as compared to a dilution proportional to $t^{-1}$. All the above observations can be explained by treating the plume as a radiative-convective mixed layer similar to the 1991 Kuwait oil fire plumes.

Based on the knowledge available about forest fire plumes, a considerable uncertainty in the temporal development of the plumes microphysical properties remains, mainly caused by the uncertainty of the dilution as a function of time. The dilution again determines the coagulation rate in the plume and the efficiency with which the external mixture of absorbing forest fire and non-absorbing background particles becomes internally mixed. The uncertainty in the coagulation rate causes an uncertainty in the plume's radiative forcing of $20-40 \%$, the uncertainty in the state of mixture of a factor of 5-6. Global circulation models should consider this effect when predicting the radiative forcing of forest fire aerosol.

The recent report by the Intergovernmental Panel on Climate Change (IPCC, 2001) states that biomass burning, with a significant contribution of forest fires, is one of the important but rather uncertain climate forcing agents. Despite considerable efforts in the past and resulting certainty about the properties of forest fire aerosol, the uncertainty with which the radiative forcing of this aerosol can be predicted remains high. In order to improve the understanding of the relevant processes, quasi-Lagrangian in situ measurements of the microphysical and optical particle properties as well as of the condensable and precursor gases should be conducted within forest fire plumes following the plume over several days. These in situ measurements need to be supported by predictive models and satellite data to follow the plume and guide the in-situ measurements. Also, transport-coupled aerosol models are necessary to interpret the measurements. Such experiments could help to reduce the uncertainty in prediction of the radiative forcing by forest fire aerosol.

Acknowledgements. This study was supported in parts by the "Deutsches Bundesministerium für Bildung und Forschung" $(\mathrm{BmB}+\mathrm{F})$ under contract number 07AF115/2.

\section{References}

Ackerman, T. P. and Toon, O. B.: Absorption of visible radiation in atmosphere containing mixtures of absorbing and nonabsorbing particles, Appl. Opt., 20, 3661-3668, 1981.

Anderson, B.E., Grant, W.B., Gregory, G.L., Browell, E. V., Collins, J.E., Sachse, G.W., Bagwell, D. R., Hudgins, C.H., Blake, D. R., and Blake, N. J.: Aerosols from biomass burning over the tropical south atlantic region: Distributions and impacts, J. Geophys. Res., 101, 24 117-24 137, 1996.

Andreae, M. O.: The dark side of aerosols, Nature, 409, 671-672, 2001.
Andreae, M. O., Fishman, J., and Lindesay, J.: The southern tropical region experiment (STARE): Transport and atmospheric chemistry near the equator-atlantic (TRACEA) and southern african fire-atmosphere research initiative (SAFARI): An introduction, J. Geophys. Res., 101, 23 519-23 520, 1996.

Ansmann, A., Leiterer, U., Wandinger, U., and Wiedensohler, A.: Lindenberg aerosol characterization experiment 1998: Overview, J. Geophys. Res., 107, 10.1029/2000JD000 233, 2002.

Arya, S. P.: Air pollution meteorology and dispersion, Oxford University Press, New York, 1999.

Bond, T.C., Anderson, T.L., and Campbell, D.: Calibration and intercomparison of filter-based measurements of visible light absorption by aerosols, Aerosol Sci. Technol., 30, 582-600, 1999.

Chylek, P. and Wong, J.: Effect of absorbing aerosols on global radiation budget, Geophys. Res. Lett., 22, 929-931, 1995.

Fiebig, M., Petzold, A., Wandinger, U., Wendisch, M., Kiemle, C., Stifter, A., Ebert, M., Rother, T., and Leiterer, U.: Optical closure for an aerosol column: method, accuracy, and inferable properties, applied to a biomass burning aerosol and its radiative forcing, J. Geophys. Res., 107, 10.1029/2000JD000 192, 2002.

Fishman, J., Hoell, J. M., Bendura, R. D., McNeal, R. J., and Kirchhoff, V. W. J. H.: NASA GTE TRACE A experiment (septemberOctober 1992): Overview, J. Geophys. Res., 101, 23 865-23 879, 1996.

Formenti, P., Boucher, O., Reiner, T., Sprung, D., Andreae, M. O., Wendisch, M., Wex, H., Kindred, D., Tzortziou, M., Vasaras, A., and Zerefos, C.: STAAARTE-MED 1998 summer airborne measurements over the Aegean Sea: 2. aerosol scattering and absorption, and radiative calculations, J. Geophys. Res., 107, DOI: 10.1029/2001JD001 536, 2002a.

Formenti, P., Reiner, T., Sprung, D., Andreae, M. O., Wendisch, M., Wex, H., Kindred, D., Dewey, K., Kent, J., Tzortziou, M., Vasaras, A., and Zerefos, C.: STAAARTE-MED 1998 summer airborne measurements over the Aegean Sea: 1. aerosol particles and trace gases, J. Geophys. Res., 107, DOI: 10.1029/2001JD001337, 2002b.

Forster, C., Wandinger, U., Wotawa, G., James, P., Mattis, I., Althausen, D., Simmonds, P., O'Doherty, S., Jennings, S. G., Kleefeld, C., Schneider, J., Trickl, T., Kreipl, S., Jäger, H., and Stohl, A.: Transport of boreal forst fire emissions from Canada to Europe, J. Geophys. Res., 106, 22 887-22 906, 2001.

Fromm, M., Alfred, J., Hoppel, K., Hornstein, J., Bevilacqua, R., Shettle, E., Servranckx, R., Li, Z., and Stocks, B.: Observations of boreal forest fire smoke in the stratosphere by POAM III, SAGE II, and lidar in 1998, Geophys. Res. Lett., 27, 1407$1410,2000$.

Gassó, S. and Hegg, D. A.: Comparison of columnar aerosol optical properties measured by the MODIS airborne simulator with In Situ measurements: A case study, Remote Sens. Environ., 66, 138-152, 1999.

Haywood, J. M. and Shine, K. P.: The effect of anthropogenic sulfate and soot aerosol on the clear sky planetary radiation budget, Geophys. Res. Lett., 22, 603-606, 1995.

Herring, J. A. and Hobbs, P. V.: Radiatively driven dynamics of the plume from 1991 Kuwait oil fires, J. Geophys. Res., 99, 18 809$18826,1994$.

Hobbs, P. V., Reid, J. S., Herring, J. A., Nance, J. D., Weiss, R. E., Ross, J. L., Hegg, D. A., Ottmar, R. D., and Liousse, C.: Particle and trace-gas measurements in the smoke from prescribed burns 
of forest products in the pacific northwest, in Biomass Burning and Global Change, edited by J.S. Levine, MIT Press, 2, 66, 697-715, 1996.

Hsu, N.C., Herman, J. R., Gleason, J.F., Torres, O., and Seftor, C. J.: Satellite detection of smoke aerosols over a snow/ice surface by TOMS, Geophys. Res. Lett., 26, 1165-1168, 1999.

IPCC: Climate Change 2001: The Scientific Basis, Cambridge University Press, Cambridge, 2001.

Jacobson, M.J.: Strong radiative heating due to the mixing state of black carbon in atmospheric aerosols, nature, 409, 695-697, 2001.

Kaufman, Y. J., Setzer, A., Ward, D., Tanre, D., Holben, B. N., Menzel, P., Pereira, M. C., and Rasmussen, R.: Biomass burning airborne and spaceborne experiment in the amazonas (BASE-A), J. Geophys. Res., 97, 14 581-14 599, 1992.

Kaufman, Y. J., Remer, L. A., Ottmar, R. D., Ward, D. E., Li, R. R., Kleidman, R., Fraser, R. S., Flynn, L., McDougal, D., and Shelton, G.: Relationship between remotely sensed fire intensity and rate of emission of smoke: SCAR-C experiment, in Biomass Burning and Global Change, edited by J. S. Levine, MIT Press, 2, 65, 685-696, 1996.

Kaufman, Y. J., Hobbs, P. V., Kirchhoff, V. W. J. H., Artaxo, P., Remer, L. A., Holben, B. N., King, M. D., Ward, D. E., Prins, E. M., Longo, K. M., Mattos, L. F., Nobre, C. A., Spinhirne, J. D., Ji, Q., Thompson, A. M., Gleason, J.F., Christopher, S. A., and Tsay, S.-C.: Smoke, clouds, and radiation-brazil (SCAR-B) experiment, J. Geophys. Res., 103, 31 783-31 808, 1998.

Le Canut, P., Andreae, M. O., Harris, G. W., Wienhold, F. G., and Zenker, T., Aerosol optical properties over southern africa during SAFARI-92, in Biomass Burning and Global Change, edited by J. S. Levine, MIT Press, 1, 42, 441-459, 1996.

Lilly, D. K.: Cirrus outflow dynamics, J. Atmos. Sci., 45, 1594 1605, 1988.

Lindesay, J.A., Andreae, M.O., Goldammer, J.G., Harris, G., Annegarn, H. J., Garstang, M., Scholes, R. J., and van Wilgen, B.W.: International geosphere-biosphere programme/international global atmospheric chemistry SAFARI-92 field experiment: Background and overview, J. Geophys. Res., 101, 23 521-23 530, 1996.

Myhre, G., Stordal, F., Restad, K., and Isaksen, I. S. A.: Estimation of the direct radiative forcing due to sulfate and soot aerosols, Tellus, 50B, 463-477, 1998.

Penner, J. E., Chuang, C. C., and Grant, K., Climate forcing by carbonaceous and sulfate aerosols, Clim. Dyn., 14, 839-851, 1998.

Petzold, A., Fiebig, M., Flentje, H., Keil, A., Leiterer, U., Schröder, F., Stifter, A., Wendisch, M., and Wendling, P.: Vertical variability of aerosol properties observed at a continental site during the lindenberg aerosol characterization experiment (LACE 98), J. Geophys. Res., 107, 10.1029/2001JD001 043, 2002.

Reid, J.S. and Hobbs, P. V.: Physical and optical properties of young smoke from individual biomass fires in Brazil, J. Geophys. Res., 103, 32 013-32 030, 1998.
Reid, J.S., Hobbs, P. V., Ferek, R. J., Blake, D. R., Martins, J. V., Dunlap, M.R., and Liousse, C.: Physical, chemical, and optical properties of regional hazes dominated by smoke in Brazil, J. Geophys. Res., 103, 32 059-32 080, 1998.

Schult, I., Feichter, J., and Cooke, W. F.: Effect of black carbon and sulfate aerosols on the global radiation budget, J. Geophys. Res., 102, 30 107-30 117, 1997.

Seinfeld, J.H. and Pandis, S. N.: Atmospheric chemistry and physics: From air pollution to climate change, John Wiley \& Sons, New York, 1998.

Sellers, P. J., Hall, F. G., Kelly, R.D., Black, A., Baldocchi, D., Berry, J., Ryan, M., Ranson, K. J., Crill, P. M., Lettenmaier, D. P., Margolis, H., Cihlar, J., Newcomer, J., Fitzjarrald, D., Jarvis, P. G., Gower, S. T., Halliwell, D., Williams, D., Goodison, B., Wickland, D.E., and Guertin, F.E.: BOREAS in 1997: Experiment overview, scientific results, and future directions, J. Geophys. Res., 102, 28 731-28 769, 1997.

Toon, O. B., Pollack, J. B., and Khare, B. N.: The optical constants of several atmospheric aerosol species: Ammonium sulfate, aluminum oxide, and sodium chloride, J. Geophys. Res., 81, 57335748, 1976.

Wandinger, U., Müller, D., Böckmann, C., Althausen, D., Matthias, V., Bösenberg, J., Weiß, V., Fiebig, M., Wendisch, M., Stohl, A., and Ansmann, A.: Optical and microphysical characterization of biomass-burning and industrial-pollution aerosols from multiwavelength lidar and aircraft measurements, J. Geophys. Res., 107, 10.1029/2000JD000 202, 2002.

Ward, D.E., Susott, R. A., Kauffman, J.B., Babbitt, R.E., Cummings, D. L., Dias, B., Holben, B.N., Kaufman, Y.J., Rasmussen, R. A., and Setzer, A. W.: Smole and fire characteristics for cerrado and deforestation burns in brazil: BASE-B experiment, J. Geophys. Res., 97, 14 601-14 619, 1992.

Wendisch, M., Heintzenberg, J., and Bussemer, M.: Measurementbased aerosol forcing calculations: The influence of model complexity, Meteor. Z., 10, 45-60, 2001.

Wendisch, M., Keil, A., Müller, D., Wandinger, U., Wendling, P., Stifter, A., Petzold, A., Fiebig, M., Wiegner, M., Freudenthaler, V., Armbruster, W., von Hoyningen-Huene, W., and Leiterer, U.: Aerosol-radiation interaction in the cloudless atmosphere during LACE 98 Part 1: Measured and calculated broadband solar and spectral surface insolations, J. Geophys. Res., 107, 10.1029/2000JD000 226, 2002

Wendling, P., Stifter, A., Petzold, A., Fiebig, M., Kiemle, C., Flentje, H., Wendisch, M., Ansmann, A., Armbruster, W., Leiterer, U., and v. Hoyningen Huene, W.: Aerosol-radiation interaction in the cloudless atmosphere during LACE 98 Part 2: Aerosol induced radiative flux changes determined from airborne pyranometer measurements and calculations, J. Geophys. Res., 107, 10.1029/2000JD000 288, 2002 